University of Wollongong

Research Online

Faculty of Social Sciences - Papers (Archive) Faculty of Arts, Social Sciences \& Humanities

2012

Uncanny Animals: Thinking Differently About Ethics and the Animal-Human Relationship

Rob Irvine

University of Sydney

Christopher J. Degeling

University of Wollongong, degeling@uow.edu.au

lan Kerridge

University of Sydney

Follow this and additional works at: https://ro.uow.edu.au/sspapers

Part of the Education Commons, and the Social and Behavioral Sciences Commons

Research Online is the open access institutional repository for the University of Wollongong. For further information contact the UOW Library: research-pubs@uow.edu.au 


\title{
Uncanny Animals: Thinking Differently About Ethics and the Animal-Human Relationship
}

\author{
Abstract \\ Maintaining the attention to bodily difference human and animal ontology has long been constructed on \\ rigid physical characterizations seemingly untouched by culture. In "Reframing the Ethical Issues in Part- \\ Human Animal Research," Haber and Benham (2012) call into question most of the formal elements of \\ essentialism that an earlier mode of thought took for granted. Two views on the nature of human and \\ interspecies animal bodies are in contention here. The first offers an argument grounded in the essential \\ developmental properties of human and animal material and biological systems such that giving life to \\ "animals with human derived material," exemplified by animal-human hybrids and chimeras, effaces \\ physical distinctions between animal and human. Dualism is invoked as an interpretive aid, structuring \\ thought and shaping understanding. Against nonhuman animals, human life, in all its stages and forms, \\ uniquely requires some fundamental form of moral consideration. Because of this presumptive obligation, \\ an "inexorable moral confusion" is an inevitable by-product of scientific change, since fixed constructions \\ of animal and human bodies as unified and separate wholes are lost in any clear-cut sense (Robert and \\ Baylis 2003).

\section{Disciplines} \\ Education | Social and Behavioral Sciences

\section{Publication Details} \\ Irvine, R., Degeling, C. \& Kerridge, I. (2012). Uncanny Animals: Thinking Differently About Ethics and the \\ Animal-Human Relationship. The American Journal of Bioethics, 12 (9), 30-32.
}


This is an Accepted Manuscript of an article published in the American Journal of Bioethics on 10 August 2012, available online at http://www.tandfonline.com/doi/abs/10.1080/15265161.2012.699143

\title{
Uncanny Animals: Thinking Differently About Ethics and the Animal-Human Relationship
}

\author{
Rob Irvine , Chris Degeling \& lan Kerridge \\ Corresponding author: Rob Irvine, email: rirvine@med.usyd.edu.au
}

Maintaining the attention to bodily difference human and animal ontology has long been constructed on rigid physical characterizations seemingly untouched by culture. In "Reframing the Ethical Issues in Part-Human Animal Research," Haber and Benham (2012) call into question most of the formal elements of essentialism that an earlier mode of thought took for granted. Two views on the nature of human and interspecies animal bodies are in contention here. The first offers an argument grounded in the essential developmental properties of human and animal material and biological systems such that giving life to "animals with human derived material," exemplified by animal-human hybrids and chimeras, effaces physical distinctions between animal and human. Dualism is invoked as an interpretive aid, structuring thought and shaping understanding. Against nonhuman animals, human life, in all its stages and forms, uniquely requires some fundamental form of moral consideration. Because of this presumptive obligation, an "inexorable moral confusion" is an inevitable by-product of scientific change, since fixed constructions of animal and human bodies as unified and separate wholes are lost in any clear-cut sense (Robert and Baylis 2003). The uncanniness of animals with human parts is not, therefore, simply a product of the tension between the familiarity and foreignness of their appearance and nature. Rather, their very existence disrupts a priori assumptions about how the world is and ought to be ordered; belief systems that are central to understandings of what it means to be human and humanity's sense of distinctiveness.

The second perspective recalibrates discussion about the nature of the animal and the human. Haber and Benham (2012) take aim at what they describe as the "naive developmental essentialism" around which previous resistance to human-animal interspecies research has been organized. Essentialist arguments, they say, do not so much problematize but hide the "true" ontological nature of human-animal hybrids. Arguing that developmental biology provides a more accurate account of the "inner truth" of animals with human-derived material, Haber and Benham (2012) find that normative "uncertainties" rather than "moral confusion" figures along the biomedical frontier, such that there is a complete subversion of the notion of unconnected categories, of clear-cut differences that are marked by impregnable and obvious boundaries. Rather than inexorable moral confusion, a narrative of uncertainty in human-to-nonhuman interspecies research, they argue, offers a more finely tuned and truthful, and therefore effective, oppositional discourse founded on good biological science.

What animals in general and interspecies animals in particular share in both of the oppositional narratives just outlined is a normative conception of human biology and human life that presupposes an impetus toward the marginalization of nonhuman animal life. In terms of ethical application, Haber and Benham (2012) continue to frame their oppositional narrative in terms that keep an unequivocal distinction between human and animal in place.

We differ from Haber and Benham (2012) in that where they see uncertainty or confusion, we see opportunity. Because interspecific animals materialize new forms of embodied relationship, the moral task that surround animals with human parts should not simply rest on how to categorize or 
taxonomize new types of things. Rather, it could plausibly involve a deeper reading of how nonhuman life is typically situated in normative deliberations, and specifically how we should think about our ethical obligations to animals.

Animals with human parts are not simply a source of ontological insecurity or uncertainty, nor are they a category or class of a certain kind of body, but a point of intellectual departure, a sign that a paradigmatic shift in bioethical thought is required. This does not mean that existing philosophical reflections on the moral status of animals have contributed nothing, or that we need to "rip it up and start again," but rather, that a new approach to the ethical dimensions of our relationships with nonhuman animals is needed-one that helps us rethink the underlying ontological, epistemological, and ethical assumptions dominating existing bioethical analysis. Animals that are part of, but separate from, us create conditions of possibility for thinking otherwise: thinking differently beyond the boundaries of familiar narratives that construct the nonhuman animal as "Other," as entities completely separate from us.

Much of this work has already begun. Theoretical projects have been developed that interrogate paradigms of Western ethics inherited from humanist discourse and question whether these discourses are adequate for an understanding the relationship between animals and humans. Breaking down the binary categories of human-animal as a basis for normative deliberation, writers like Cora Diamond, Cary Wolfe, Martha Nussbaum, and others draw our gaze to fundamental continuities between human lives and the lives of other animals. For example, Diamond (1978) contends that animals are morally considerable based upon our intuitive perception of them as "fellow creatures" who share a like existence, "being in a certain boat ... as our fellows in mortality in life on this earth" as "human beings" who are intrinsically valuable qua "human beings" (Diamond 1978 , 474). This nonbiological relationship and our recognition of our own vulnerability-that is shared between animal and human-is what freights our sense of moral consideration and generates our moral response to animals and their treatment (Diamond 2001, 121). Or it should.

Like Diamond, Cary Wolfe (2010) focuses our attention on "personhood." Appealing to epistemology and scientific evidence, he "disarticulates" the question of "persons" from species membership. Our relationship with them is grounded in what he describes as our "shared finitude": Animals are first and foremost living beings and they share with us ontological vulnerability. Both human and nonhuman animals share the physical processes of aging, decline, and death (Wolfe 2010, 77, 139). This joint focus allows for a more serious consideration of nonhuman animals subjects founded on common vulnerabilities of the body and bodily suffering.

Martha Nussbaum (2006), likewise, abandons assumptions of human exceptionalism to interrogate the consequentialist tropes that dominate current justifications for the continued utilization of nonhuman animals for human purposes. By taking a neo-Aristotelian approach that focuses on more than the moral significance of sentience she shows how "other" types of being (those that cannot fairly participate in a socio-moral contract founded on reciprocity and mutual benefit) are denied the possibility of justice, and therefore the capacity to flourish to their full potential. In this, Nussbaum shares with Diamond and Wolfe a concern for the continuities between human and nonhuman animals. Rather than biological identity or rationality, she posits dignity as one of the properties, or capabilities, we share with other species: our needs, capacity for pain, and the innate complexity and communitarian nature of being alive.

These narratives mark a significant change in the way we think of nonhuman animals and of their moral status. Creatively rewriting ethical conversations about nonhuman animals, each narrative demands that we think "otherwise" about animals and our relationship with them. While acknowledging the limits of our knowing, these narratives invite us to transcend species limits and reimagine nonhuman animals beyond their position as "other": to consider alternative ways of imagining, articulating, and valuing nonhuman animals and negotiating the animal-human relationship, mediated by recognition of a kind of kinship with animals beyond the species barrier. Such a commitment opens up new creative prospects of understanding that emphasize such human 
social values as compassion (Wolfe 2010, 77), justice (Diamond 2001), sympathy (Butler 2004, 26), and reciprocity and obligation (Nussbaum 2006), worked out without recourse to old binaries of animal-human.

Haber and Benham offer a starting point for the analysis of interspecies animal research that comes at the cost of ignoring the animal itself. But it will eventually be necessary to consider further the ethical implications of existence of these indeterminate creatures and to treat them, as all animals, as if they matter. These seemingly familiar yet foreign creatures can do much to further the development of our collective moral experience and lay the groundwork for new questions to be asked: How are we to deal with the animal "Other" when it is never, after all, completely "other"?

\section{REFERENCES}

Butler, J. 2004. Precarious life: The power of morning and violence, New York, NY: Verso.

Diamond, C. 1978. Eating meat and eating people. Philosophy, 53: 465-479.

Diamond, C. 2001. "Injustice and animals". In Slow cures and bad philosophers: Essays on Wittgenstein, medicine, and bioethics, Edited by: Elliott, Carl. 118-148. Durham, NC: Duke University Press.

Haber, M. H. and Benham, B. 2012. Reframing the ethical issues in part-human animal research: The unbearable ontology of inexorable moral confusion. American Journal of Bioethics, 12(9): 17-25.

Nussbaum, M. 2006. Frontiers of justice: Disability, nationality, species membership, Cambridge, MA: Harvard University Press.

Robert, J. S. and Baylis, F. 2003. Crossing species boundaries. American Journal of Bioethics, 3(3): 113.

Wolfe, C. 2010. What is posthumanism?, Minneapolis: University of Minnesota Press. 